plasma renin concentration alone provides an overlapping zone. Moreover, effective plasma renin correlates significantly with mean blood pressure, whereas plasma renin concentration alone does not.

The reason for the inappropriately high plasma renin concentration for the level of exchangeable sodium is probably due to other factors known to stimulate renin secretion. Included in these factors is ischaemia of the juxtaglomerular apparatus. Our experience that patients with resistant hypertension show more proliferation of the intima of the intrarenal arterioles supports this idea.

We wish to thank the staff of the M.R.C. High Blood Pressure Unit, Glasgow, for their helpful discussion, and Dr. M. Tree for performing the renin estimations.

This work was supported by the Leeds Kidney Research Fund, Leeds and West Riding Medical Trust, and Leeds Regional Hospital Board.

Requests for reprints should be addressed to: Dr. S. M. Rosen, Leeds (St. James's) University Hospital, Leeds LS9 7TF.

\section{References}

Bianchi, G., Brown, J. J., Lever, A. F., Robertson, J. I. S., and Roth, N. (1968). Clinical Science, 34, 303

Bianchi, G., et al. (1972). Clinical Science, 42, 47.

Blumberg, A., Nelp, W. P., Hegstrom, R. M., and Scribner, B. H. (1967) Lancet, $2,69$.

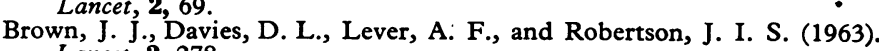
Lancet, 2,278

Brown, J. J., Davies, D. L., Lever, A. F., Robertson, J. I. S., and Tree, M. (1964). Biochemical fournal, 93, 594

Brown, J. J., et al. (1969). Nephron, 6, 329.

Brown, J. J., et al. (1971). British Medical Bulletin, 27, 128.

Bull, M. B., Hillman, R. S., Cannon, P. J., and Laragh, J. H. (1970). Circulation Research, 27, 953.

Craswell, P. W., et al. (1972). British Medical fournal, 4, 749.

Davies, D. L., et al. (1973). Lancet, 1, 683.

Edwards, K. D. G., and White, H. M. (1959). Clinical Science, 18, 361.

Goss, J. E., Alfrey, A. C., Vogel, J. H. K., and Holmes, J. H. (1967). Transactions. American Society for Artificial Internal Organs, 13, 68.

Onesti, G., Swartz, C., Ramirez, O., and Brest, A. N. (1968). Transactions. American Society for Artificial Internal Organs, 14, 361

Reubi, F., Butkofer, E., and Vorburger, C. (1970). Actualités Néphrologiques de l'Hôpital Necker, p. 47.

Shaldon, S., Rae, A. I., Rosen, S. M., Silva, H., and Oakley, J. (1963). British Medical fournal, $1,1716$.

Vertes, V., Cangiano, J. L., Berman, L. B., and Gould, A. (1969). New England Fournal of Medicine, 280, 978

Veyrat, R., De Champlain, J., Boucher, R., and Genest, J. (1964). Canadian Medical Association fournal, 90, 215.

Wilkinson, R., Scott, D. F., Uldall, P. R., Kerr, D. N. S., and Swinney, J. (1970). Quarterly fournal of Medicine, 39, 377.

\title{
Single-dose, "Block-Replace" Drug Therapy in Hyperthyroidism
}

\author{
P. H. WISE, MILLICENT MARION, R. W. PAIN
}

British Medical fournal, 1973, 4, 143-145

\section{Summary}

In 30 consecutive hyperthyroid patients with diffuse goitre divided dose therapy with carbimazole $40 \mathrm{mg}$ and triiodothyronine $80 \mu \mathrm{g}$ daily was shown to produce total or subtotal block in thyroid hormonogenesis. Once produced, this block could be invariably maintained with an equivalent single daily dose for periods up to three years. Its notable acceptability to patients, a more stable degree of euthyroid control, ease of assessing suppressibility of trapping, and ability to treat patients in remote areas all support a wider use of this mode of therapy.

\section{Introduction}

In the drug treatment of hyperthyroidism it has been customary to use thiourea derivatives in a divided daily regimen, titrating dosage against clinical and biochemical thyroid status and only occasionally adding thyroid hormone replacement to prevent or correct iatrogenic hypothyroidism.

This approach carries certain disadvantages-the need for periodic and sometimes frequent evaluation to prevent swings

Royal Adelaide Hospital, Adelaide, South Australia

P. H. WISE, M.R.C.P., F.R.A.C.P., Director of Endocrinology

Institute of Medical and Veterinary Science, Adelaide, South Australia

MILLICENT MARION, M.B., B.S., Physician in Nuclear Medicine R. W. PAIN, M.B., F.R.C.P.A., Clinical Chemist (Medical)

in thyroid status and the unreliability of clinical assessment of euthyroidism, especially when using propylthiouracil (Christensen et al., 1969) and in the early months of treatment where normal serum thyroxine (T-4) levels may not reflect euthyroid secretory pattern to disproportionately high triiodothyronine (T-3) concentrations (Bellabarba et al., 1972). Furthermore, desired dose frequency is sometimes not adhered to, and the nuisance value of divided daily dosage can act as an incentive for subtotal thyroidectomy when on other grounds surgery may not be indicated.

The purpose of this study was to assess the efficacy of a regimen designed to block thyroid hormone synthesis as completely as possible using carbimazole while maintaining constant euthyroidism by replacement with triiodothyronine, both drugs being subsequently given in single daily dosage.

\section{Subjects and Methods}

After feasibility studies had been carried out in eight subjects with varying doses of carbimazole, 30 consecutive hyperthyroid patients aged 40 years or less with isotopically proved diffuse thyroid enlargement were studied. Clinical assessments were carried out by one observer (P.H.W.).

Total serum thyroxine was estimated by the method of Murphy (1965) (95\% confidence limits for euthyroidism: $6 \cdot 4-12 \cdot 0 \mu \mathrm{g} / 100 \mathrm{ml}$ ), and thyrobinding index (T.B.I.) by the method of Oldfield and Pain (1969) (95\% confidence limits for euthyroidism: $0 \cdot 85-1 \cdot 15)$; a free thyroxine index (F.T.I.) was derived from the ratio T-4/T.B.I. ( $95 \%$ confidence limits for euthyroidism: $6 \cdot 3-12 \cdot 3)$. Technetium $\left({ }^{99 m} \mathrm{Tc}\right)$ uptake test and simultaneous scintiscanning were performed with a Nuclear Chicago gamma camera 40 minutes after an intravenous dose of ${ }^{99 \mathrm{~m} T c}$ (Wise et al., 1973) (95\% confidence limits for euthyroidism: $2 \cdot 0-6 \cdot 0 \%$ of dose). 
PROCEDURE

Initial hyperthyroidism was confirmed by a free thyroxine index of $33 \cdot 1 \pm 12 \cdot 1$ units (mean \pm S.D.), with pretreatment ${ }^{99} \mathrm{~m} \mathrm{Tc}$ uptake ranging from $8 \%$ to $36 \%$ at 40 minutes. In all cases theiapy was started with carbimazole $10 \mathrm{mg}$ and triiodothyronine $20 \mu \mathrm{g}$, each given as close as possible to six-hourly.

Clinical status and biochemical thyroid function were assessed every two to three months. Once the free thyroxine index had fallen to 5 units or below, carbimazole $40 \mathrm{mg}$ and thyroxine $80 \mu \mathrm{g}$ were given in a single daily dose between 06.30 and 08.00 hours daily, and this was continued with threemonthly clinical and biochemical assessment. Suppressibility of thyroid trapping was arbitrarily defined as a lowering of thyroidal ${ }^{99} \mathrm{mTc}$ uptake to $5 \%$ or less of the administered dose in the course of the above treatment regimen; this procedure was performed every three to six months.

\section{Results}

The rate of clinical improvement appeared to be more rapid than with previously used "titration" doses of carbimazole, all patients being clinically euthyroid two months after starting therapy. In every subject the free thyroxine index fell to 5 units or less within three months (fig. 1), with a mean value of $3.8 \pm 0.6$ units. The change to single daily dosage could therefore be undertaken after three months of divided dosage in all cases; earlier transfer was not attempted. The change to single daily dosage was associated with neither loss of clinical control nor diminution in degree of thyroidal block as assessed biochemically (free thyroxine index $3.7 \pm 0.7$ ) (fig. 1). On prolonged follow-up for a maximum of three years there was no evidence of loss

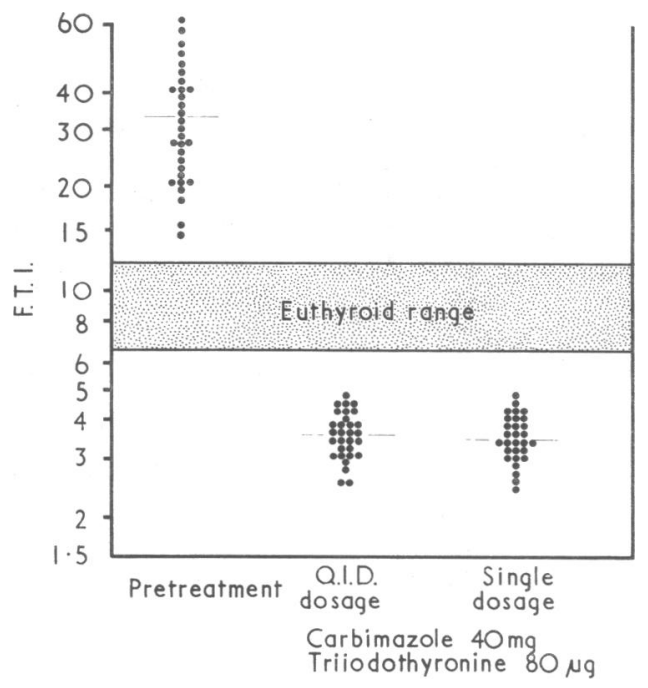

FIG. 1-Free thyroxine indices in identical subjects on six-hourly and single-dose block-replace therapy.

of control; in fact, there was a slight fall in the mean free thyroxine index (fig. 2). Ability to maintain thyroidal block was shown to be independent of suppressibility of trapping (see table), indicating that ease of control on a single daily dose did not reflect a gland in "remission."

Comparison of Suppressibility with Effective Blocking

\begin{tabular}{ll|c|c|c|c}
\hline & $\begin{array}{c}\text { No. of } \\
\text { Cases }\end{array}$ & $\begin{array}{c}\text { Mean }{ }^{99} \text { mTc } \\
\text { Uptake (Range) }\end{array}$ & $\begin{array}{c}\text { F.T.I. } \\
\text { (Mean } \pm \text { S.D. })\end{array}$ & $P$ \\
$\ldots$ Son-suppressible & $\cdots$ & 22 & $\begin{array}{c}3.5 \%(1.6-5.0 \%) \\
13.9 \%(7.9-35.0 \%)\end{array}$ & $\begin{array}{c}3.5 \pm 0.8 \\
3.5 \pm 0.6\end{array}$ & \}$>0.1$ \\
\hline
\end{tabular}

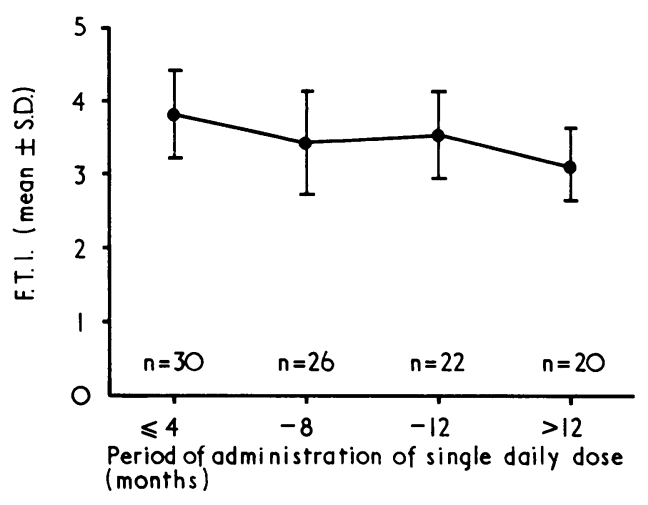

FIG. 2-Effect of duration of therapy on maintenance of thyroidal block.

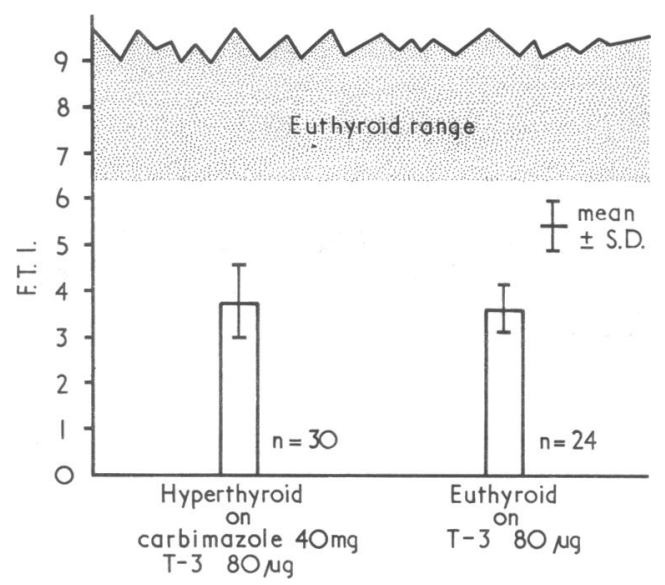
FIG. 3-Free thyroxine indices in "blocked-replaced"
hyperthyroid subjects compared with indices in "suppressed" euthyroid subjects.

Hypothyroid levels of the free thyroxine index during treatment confirmed subtotal block of hormone synthesis. To provide an additionai assessment of completeness of block the following procedure was undertaken. The mean free thyroxine index in the above treated hyperthyroid patients was compared with the mean index in a group of subjects with simple obesity during treatment with triiodothyronine $80 \mu \mathrm{g}$ daily for a minimum period of three months. The respective values for these groups $(3 \cdot 7 \pm 0.7 ; 3.6 \pm 0.6)$ did not differ significantly $(P>0.1)$ (fig. 3 ). This suggests that the $40 \mathrm{mg}$ dose of carbimazole was as effective in reducing circulating thyroxine levels as a dose of triiodothyronine, known from other studies to be almost invariably capable of suppressing production of thyroid stimulating hormone (Cotton et al., 1971).

It should be noted that all the stated free thyroxine indices were based on thyroxine assays which employed extrapolations from the usual linear form of standard "curve" and therefore falsely raised any thyroxine values falling within the hypothyroid range. Accordingly a thyroxine assay using a precise sigmoid standard curve, employing multiple concentrations of thyroxine standard from zero to $15 \mu \mathrm{g} / 100 \mathrm{ml}$, was set up for 12 sera from patients on block-replace therapy. A "true" free thyroxine index of $1.3 \pm 0.4$ compared with a "standard" index of $3.3 \pm 0.5$ was obtained on this group, thereby providing a better indication of the degree of impairment of hormone synthesis achieved by this therapy.

All patients volunteered appreciation of single daily dosage, and in eight cases a further improvement in patient acceptance was achieved through the use of specially prepared capsules 
containing carbimazole $10 \mathrm{mg}$ and triiodothyronine $20 \mu \mathrm{g}$. All patients were willing to continue single-dose therapy indefinitely. One patient developed a typical erythematous rash and migratory polyarthralgia assumed to represent hypersensitivity to carbimazole and was transferred, with maintenance of block, to propylthiouracil in divided dosage. Conversion to equivalent single daily dosage of this drug ( $400 \mathrm{mg})$, however, was associated with loss of control, and the patient subsequently requested surgical management.

\section{Discussion}

Despite the lack of conclusive evidence on either teratogenicity or carcinogenicity resulting from radioiodine therapy for hyperthyroidism it is still generally considered inadvisable to use this mode of therapy in the reproductive age group. Recurrence rates after subtotal thyroidectomy $(14 \%)$ and the incidence of postoperative hypothyroidism $(25 \%)$, both reported in a series of 5,221 subjects in a multicentre study (Becker et al., 1971), suggest that there is a continued place for prolonged antithyroid therapy in many cases of hyperthyroidism. Methods which improve stability of control, reduce doctor or hospital visits to a minimum, and improve patient acceptance justify close examination.

Two previous studies of relevance have been reported. Greer et al. (1965) used single daily doses of propylthiouracil or methimazole and claimed control in 29 out of 31 cases; however, no laboratory data were included to support this claim and titration of dose against clinical and biochemical status was still employed. More recently Kammer and Srinivasan (1969) reported that out of 41 patients controlled on propylthiouracil in divided doses, 28 were able to continue on single daily doses with clinical and biochemical control using doses of up to $400 \mathrm{mg}$ daily. In that paper it was suggested that methimazole, the active metabolite of carbimazole, could prove more effective for single-dose therapy because of its longer duration of action (Stanley and Astwood, 1949). Recent studies confirm selective binding of both methimazole and propylthiouracil into thyroid tissue (Pittman et al., 1971), and the data of Wartofsky and Ingbar (1971) indicate a duration of action of a single dose of $30 \mathrm{mg}$ methimazole of 24-36 hours despite the shorter biological half-life when assessed on blood levels. This indicates that single daily administration of these drugs in sufficient dosage should indeed be effective in adequately inhibiting thyroid hormone biosynthesis.

Barnes and Bledsoe (1972) described an overall $68 \%$ response rate to single-dose methimazole therapy and suggested that high perchlorate discharge provided a positive discriminant for such responses. The universal ability to maintain block with single-dose therapy in the present series may be based on the slightly higher doses of antithyroid drug used, a presently undefined advantage of carbimazole compared with its metabolite methiamzole, or on adequate thyroidal block shown before the change from divided to single daily dosage.

Though divided doses of carbimazole up to $60 \mathrm{mg}$ daily are occasionally necessary to achieve adequate blocking this was not found in the present consecutive series. Whether such higher doses would allow conversion to single-dose administration remains to be seen. Though triiodothyronine $80 \mu \mathrm{g}$ daily was accepted as close to the expected replacement dosage at initiation of this study in 1970, subsequent studies utilizing the principle of plasma thyrotrophin responsiveness to intravenous thyrotrophin-releasing hormone (Schenkman et al., 1973) should help in determining precisely whether this dosage of triiodothyronine is physiologically correct in patients with subtotally blocked glands. Current limited studies in this unit suggest that the present $80 \mu \mathrm{g}$ dose may be excessive replacement even in totally athyroid subjects.

The point at which to stop antithyroid therapy is controversial, and this problem falls outside the scope of this report. Nevertheless, suppressibility of thyroid trapping assessed at intervals after starting therapy has been used as a basis for termination of therapy (Alexander et al., 1970). The constant administration of triiodothyronine in the above treatment regimen allows easy assessment of such suppressibility without need for change in drug procedure. The rate of achievement of suppressibility in an extended series treated in this manner will be reported later.

The above treatment programme has been extended to six additional hyperthyroid patients with multinodular glands and has given equally satisfactory responses. More definitive forms of therapy, however, are likely to predominate in this variety of hyperthyroidism.

The relative stability of thyroid function with block-replace therapy has enabled biochemical and clinical assessments to be reduced with complete confidence to six-monthly or yearly intervals in 12 patients for whom antithyroid drugs provided definitive therapy. This was considered particularly valuable in six patients living remote from medical observation and laboratory facilities. Even allowing for the occasional failure of singledose, block-replace therapy likely to occur in a larger series, its acceptability to patients, together with the increasingly welldefined morbidity of subtotal thyroidectomy referred to above, suggest that this regimen might be employed with advantage on a wider scale.

We acknowledge the co-operation of the many physicians who referred the patients comprising this study to the endocrine unit, Royal Adelaide Hospital.

\section{References}

Alexander, W. D., et al. (1970). Fournal of Clinical Endocrinology, 30, 540. Barnes, H. V., and Bledsoe, T. (1972). Fournal of Clinical Endocrinology, 35, 250

Becker, D. V., et al. (1971). Abstracts of Sixth International Thyroid Conference, Vienna, 1970, p. 603.

Bellabarba, D., Bernard, B., and Langlois, M. (1972). Clinical Endocrinology, 1,345 .

Christensen, K. K., Skovsted, L., and Hansen, J. M. (1969). Acta Medica Scandinavica, 185, 483 .

Cotton, G. E., Gorman, C. A., and Mayberry, W. E. (1971). New England fournal of Medicine, 185,529 .

Greer, M. A., Meikoff, W. C., and Studer, H. (1965). New England Fournal of Medicine, 272, 888.

Kammer, H., and Srinivasan, K. (1969). Fournal of the American Medical Association, 209, 1325.

Murphy, B. E. P. (1965). Fournal of Laboratory and Clinical Medicine, 66, 161. Murphy, B. E. P. (1965). Fournal of Laboratory and Clinical Medicine, 66, 161. Pathology, 52, 118.

Pittman, J. A., Beschi, R. J., and Smitherman, T. C. (1971). Fournal of Clinical Endocrinology, 33, 182.

Schenkman, L., Mitsuma, T., and Hollander, C. S. (1973). Fournal of Clinical Investigation, 52, 205.

Stanley, M. M., and Astwood, E. B. (1949). Endocrinology, 44, 588.

Wartofsky, L., and Ingbar, S. H. (1971). Abstracts of Sixth International Thyroid Conference, Vienna, 1970, p. 24.

Wise, P. H., Ronai, P. M., and Pain, R. W. (1973). In preparation. 